\title{
PROGRAMA PARA A FORMAÇÃO DA CIDADANIA INFANTO-JUVENIL: UM \\ CAMINHO PARA A AUTONOMIA INFANTIL
}

\section{Program for the formation of the infant-youthful citizenship: a way for the infantile autonomy}

\author{
Ana Cláudia Delfini Capistrano de Oliveira* \\ Maria de Lourdes Alves Zanatta* \\ Lívia Lima \\ Maiti Mattoso Fontana ${ }^{* *+x}$ \\ Rodrigo Fuck Giostri \\ Simone Cristine Davel
}

\begin{abstract}
RESUMO
Este artigo apresenta o Programa de Formação da Cidadania Infanto-juvenil que resultou na publicação de um livro para crianças e adolescentes chamado CADERNO DE CIDADANIA. Seu objetivo principal é o fortalecimento da cidadania infanto-juvenil na perspectiva da autonomia e da emancipação da criança na sociedade brasileira, que vem sofrendo um absoluto descaso desde a gênese da própria sociedade brasileira. Para concretizar este objetivo o Caderno foi construído de forma participativa, unificando três projetos, o "Projeto Cidadania e Meio Ambiente na Escola: A Cartilha do Cidadão Mirim", "Direitos Humanos no Banco Escolar" e "Ação Cidadã: Aplicação do Estatuto da Criança e do Adolescente numa comunidade". O caderno, de maneira lúdica e interativa, integra as habilidades e competências que contribuem para a formação de cidadãos conscientes e ativos na defesa e proteção de seus direitos fundamentais e do patrimônio ambiental, fazendo da escola não apenas espaço de apreensão de informações técnico-formais, e sim de formação $e$ instrumentalização para a cidadania. O Caderno de Cidadania trabalha na perspectiva de ser um material de conteúdo transversal que poderá ser utilizado pelos professores de todas as disciplinas, bem como por facilitadores autônomos. O objetivo desse projeto é despertar a consciência crítica e estimular a autonomia, que significa mudança na organização da desigualdade social que afeta as crianças brasileiras.
\end{abstract}

Palavras-chave: Cidadania; direitos; infância e juventude.

\section{ABSTRACT}

This article presents the Program of Formation of the Infant-youthful Citizenship that resulted in the publication of a book for children and adolescents called NOTEBOOK OF CITIZENSHIP. Its main objective is to encourage the infant-youthful citizenship in the perspective of the autonomy and the emancipation of the child in the Brazilian society, whose comes suffering an absolute indifference since the beginning of Brazilian society. To materialize this objective the Notebook was constructed unifying three different projects: the Project "Citizenship and Environment in the School: The notebook of the Mirim Citizen, "Right Human beings in the Pertaining to school Bank" and "Action Citizen: Application of the Statute of the Child and the Adolescent in a community". The notebook integrates, in a playful and interactive way, the abilities that in such a way contribute for the

\footnotetext{
Mestre em Sociologia Política e professora da UNIVALI

* Mestre em Direito Internacional e professora da UNIVALI

Graduanda em Direito e bolsista do Programa de Extensão UNICIDADE

***** Graduada em Engenharia Ambiental e bolsista do Programa de Extensão UNICIDADE

****** Graduando em Direito e bolsista do Programa de Extensão UNICIDADE

**********aduanda em Direito e bolsista do Programa de Extensão UNICIDADE
} 
formation of conscientious and active citizens in the defense and protection of its basic rights and the ambient patrimony, making the school not only space of apprehension of information technician-deeds of division, and yes of formation of citizenship. The objective of this project is to awake the critic conscience and to stimulate the autonomy, which means changing the social inequality organization that affects Brazilians children.

\section{RESUMEN}

El articulo trae el Programa de Formação da Cidadania Infanto-juvenil, ha resultado en la publicación de un libro para ninõs y jovenes llamado CUADERNO DE LA CIUDADANÍA.Su objetivo principal es el fortalecimiento de la ciudadanía infanto-joven en la perspectiva de la autonomía y la emancipación del niño en la sociedad brasileña, que sigue sufriendo una indiferencia absoluta desde la genese de la sociedad. Para materializar este objetivo, el CUADERNO fue construido de forma participativa, por la unificación de tres proyectos de extensión: "Ciudadanía y medioambiente en la escuela: La cartilha del ciudadano mirim", "Derechos humanos en el banco de la escuela" y "Acción ciudadã: El uso del estatuto del niño y del adolescente en una comunidad". El cuaderno integra, de manera juguetona y interactiva, las habilidades y capacidades que contribuyen para la formación de ciudadanos concienzudos y activos en la defensa y la protección de sus derechos fundamentales y patrimonio ambiental, haciendo del espacio de la escuela no sólo de la aprehensión de la información técnico-formale y sí de la formación y del instrumentalización para la ciudadanía. El CUADERNO funciona en la perspectiva del contenido transversal que se podría utilizar por los profesores de todas las disciplinas, así como para facilitadores independientes. El objetivo del proyecto es despertar la conciencia critica y estimular la autonomia como cambio de la organización del iniquidad social que afecta a niños brasileños.

Introdução

O objetivo deste artigo é apresentar o histórico e a atuação do Programa de Formação para a Cidadania Infanto-Juvenil, projeto integrante do Programa de Extensão Unicidade da Universidade do Vale de Itajaí/Univali, em seus aspectos teóricos e práticos, por meio da utilização do Caderno de Cidadania, um livro para crianças e adolescentes utilizado em escolas municipais e entidades sociais dos municípios de Itajaí, Balneário Piçarras, Balneário Camboriú e Florianópolis, no Estado de Santa Catarina.

\section{Programa de Formação para a Cidadania Infanto-Juvenil}

Tudo começou no ano de 2002 com o Projeto "Cidadania e Meio Ambiente na Escola: A Cartilha do Cidadão Mirim", no qual se trabalhou a temática do exercício da cidadania nas questões ambientais junto aos alunos da Esco- la Básica Ariribá no Bairro Praia Brava/Itajaí/ $\mathrm{SC}$, que teve como objetivo construir conhecimentos em prol da formação do cidadão, reconhecimento e exercício de direitos/deveres e mobilização comunitária em prol da temática ambiental. Este projeto inicial integrava o Programa de Monitoramento Ambiental Voluntário (MAV) - desenvolvido pela equipe do Laboratório de Educação Ambiental (LEA) do Centro de Ciências Tecnológicas da Terra e do Mar - a fim de complementar as atividades desenvolvidas pelo mesmo, orientado à Educação Ambiental e baseando-se na formação do "Clube Olho Vivo", um clube de monitores mirins voluntários da escola. O Programa, enquanto proposta de Educação Ambiental Comunitária fundamentava-se na Pedagogia da Autonomia (que falaremos adiante) e teve como ponto de partida a realidade socioambiental da própria escola.

Se a escola, em vez de humanizar e preparar para a cidadania reforça a desigualdade social e "desciviliza" o aluno, então é preciso começar do zero. Não adianta falar de par- 
ticipação, de conscientização, aliás, uma palavra bastante problemática para uma criança ou um adolescente que não se sente assim, que não se vê nem como cidadão e nem como sujeito, nas palavras do sociólogo Pedro Demo, "cidadania é a competência humana de fazer-se sujeito para fazer história própria e coletivamente organizada."(DEMO, 1995, p.01). Essas palavras apresentam os dois pilares que norteiam o Caderno de Cidadania - em primeiro lugar, fazer-se sujeito para fazer história própria e em segundo lugar, fazer história própria mas coletivamente organizada.

Como resultado da experiência no "Clube Olho Vivo", produziu-se um modelo piloto de cartilha sobre cidadania e meio ambiente direcionada ao público infanto-juvenil que poderia ser utilizada como instrumento para a formação da consciência cidadã. Esta foi a segunda etapa do projeto na qual a proposta de Cartilha construída na Etapa 1 foi testada e aprimorada junto aos professores e alunos, para que pudesse se constituir em material pedagógico para as escolas. Visou-se, ainda, desenvolver atividades voltadas aos professores no intuito de capacitá-los para incorporar temas ligados à cidadania nas suas disciplinas, $e$ estimulá-los a uma maior interação com as atividades desenvolvidas pelo projeto.

Paralelamente a este projeto, estavam em desenvolvimento dois outros projetos de extensão em outro bairro da cidade, o Nossa Senhora das Graças, com objetivos e princípios semelhantes. O primeiro, "Apre(e)ndendo a Cidadania: Direitos Humanos no Banco Escolar" tinha seu foco de atuação na Escola Básica Carlos de Paula Seara e o segundo, "Ação Cidadã: Aplicação do Estatuto da Criança e do Adolescente numa comunidade", atuava junto à Associação de Moradores deste mesmo bairro. A forma de inserção do tema cidadania se dava, nestes projetos, de diferentes formas. No caso do primeiro, a inserção se dava mediante uma parceria com a escola para que o tema da cidadania fosse desenvolvido no ensino fundamental, a partir dos alunos da $4^{a}$ série. A equipe do projeto, juntamente com as professoras do colégio, desenvolvia temas relativos ao conceito de cidadania por meio de várias dinâmicas e técnicas para que as turmas fossem estimuladas a sintetizar o seu próprio conceito de cidadania, como princípio orientador da discussão sobre direitos humanos.

A finalização deste projeto deu-se com a organização de uma passeata da escola até a Universidade para a apresentação de todos os trabalhos elaborados pelos alunos no Auditório do Centro de Ciências Jurídicas e Sociais (CEJURPS), com a participação da Coordenadora Pedagógica da escola, dos professores, amigos e familiares das crianças, monitoras do projeto e autoridades da Univali.

O segundo projeto, desenvolvido por uma professora e uma acadêmica do curso de Ciências Sociais da Univali, "Ação Cidadã: Aplicação do Estatuto da Criança e do Adolescente numa comunidade", também possuía um diferencial de atuação no que diz respeito ao acesso à cidadania, pois seu público-alvo não eram as crianças matriculadas nas escolas, mas as crianças do bairro Nossa Senhora das Graças. Pela Associação de Moradores foi possível reunir as crianças, uma tarde por semana, para as oficinas sobre cidadania. As oficinas eram realizadas com 10 crianças entre 07 e 10 anos numa das salas da Associação com um único objetivo: apresentar o Estatuto da Criança e do Adolescente de forma lúdica e interativa para que as próprias crianças discutissem o que entendiam por cidadania, e a partir disto, desenvolver uma conversa sobre direitos e deveres.

A principal atividade desenvolvida pelas crianças era desenhar sobre cada direito estudado, de acordo com o próprio Estatuto. Com isso, duas metas eram alcançadas - a primeira era usufruir um espaço próprio da comunidade, reivindicado e legitimado por ela, porém, um espaço eminentemente de adultos. A 
segunda meta era socializar o Estatuto e permitir que cada criança se manifestasse a respeito de cada direito e de cada obrigação correspondente, a fim de enfatizar o princípio da emancipação e do direito da criança de se expressar e comunicar suas idéias a partir de sua própria vivência e da leitura que ela faz da realidade. $\mathrm{O}$ resultado disto foram desenhos, de certa forma, chocantes, que denunciavam a realidade da prostituição infantil e do alcoolismo que afetavam as famílias daquele bairro.

Diante desta realidade, era mister conjugar todos estes projetos num único programa que aprimorasse sua atuação comunitária em prol da cidadania participativa: o Programa de Formação para a Cidadania Infanto-Juvenil. Nascia, no ano de 2004, o Programa de Formação para a Cidadania Infanto-juvenil. A equipe executora do projeto é composta por professores das áreas de Direito e Ciências Sociais, juntamente com acadêmicos dos referidos cursos e do curso de Engenharia Ambiental, que atuam junto ao público-alvo para captar as principais problemáticas locais.

O ano de 2006 foi marcado pela concretização de parte importante dos objetivos do Programa. A Cartilha do Cidadão Mirim se transformou em "Caderno de Cidadania" e teve sua publicação e catalogação com uma tiragem inicial de nove (09) mil cópias com recursos da Assembléia Legislativa de Santa Catarina. São os principais objetivos do Programa de Formação para a Cidadania Infanto-Juvenil:

\subsection{Objetivos:}

- Implementar um Programa de Formação voltado ao público infanto-juvenil centrado nos Direitos Fundamentais, no Estatuto da Criança e do Adolescente e nos Direitos Socioambientais, por meio da estruturação de material didáticopedagógico intitulado Caderno de Cidadania;
- Realizar Oficinas de Capacitação para os parceiros do Programa a fim de proporcionar subsídios teóricos e práticos para a utilização do Caderno de Cidadania nos âmbitos da educação formal e comunitária com vistas à formação de multiplicadores. Até o momento foram realizadas 40 Oficinas para os atuais 12 parceiros do Programa;

- Elaboração de um Livro para Multiplicadores contendo textos e sugestões de atividades para embasar as Oficinas com o Caderno de Cidadania.

1.2 Público Alvo: 7 escolas municipais, 2 centros educacionais, 2 ONGs/associações comunitárias $e 1$ entidade de acolhimento institucional.

\subsection{Período de Realização: 03/2004 - Atual}

\section{4 Área Geográfica da Abrangência do Projeto:}

Itajaí, Balneário Piçarras, Balneário Camboriú e Florianópolis, no Estado de Santa Catarina.

O Caderno de Cidadania fundamenta-se na pedagogia da autonomia (Freire, 2002) e no princípio da cidadania participativa (Demo, 1995; Santos, 2002) a fim de quebrar o estigma da criança como "cidadã do amanhã", para a construção de uma cidadania do "presente", que contemple a criança como agente atuante e transformador, e até mesmo multiplicador de práticas e conhecimentos atinentes à sua realidade social. Desta forma, o Caderno possui conteúdos transversais que podem ser utilizados tanto pelos professores de várias disciplinas como por outros profissionais autônomos (ONGs, conselhos municipais, projetos de extensão etc.) que tenham o compromisso de utilizar o Caderno conforme as diretrizes norteadoras que são passadas em uma capacitação prévia com a equipe do Programa. O Caderno de Cidadania está dividido em de três módulos principais - Módulo Um: Cidadania e Direitos Fundamentais, Módulo Dois: Es- 
tatuto da Criança e do Adolescente e Módulo Três: Cidadania Sócioambiental.

Faz-se importante salientar que estes módulos trazem atividades que levam as crianças a criarem seus próprios conceitos. $\mathrm{O}$ material não traz nenhum conceito pronto, é necessário que as crianças juntamente com o professor/facilitador, trabalhem no sentido de conhecimento do tema abordado e a partir disto evoluam criando seus próprios conceitos de cidadania, de família, de Estatuto da Criança e do Adolescente, de Socioambientalismo e assim por diante. O que aquele livro busca é valorizar as vivências de cada criança/adolescente no sentido da compreensão e definição de conceitos a partir delas mesmas.

O primeiro módulo do Caderno traz uma discussão sobre cidadania de forma criativa, superando a velha idéia de "direitos e deveres" que tanto estigmatizou o conceito de cidadania. Esta discussão é perpassada pelo autoconhecimento, ou seja, antes de falar em cidadão a proposta é que a criança/adolescente saiba se nominar, dizer quem ela é, qual a impor-

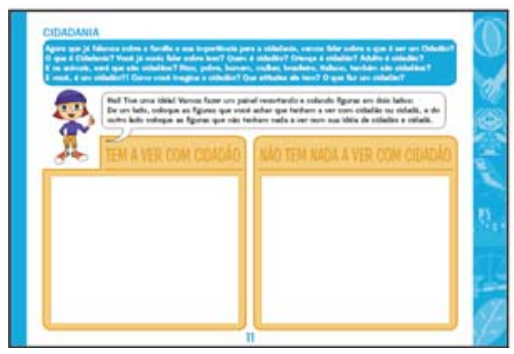

Durante todo este módulo as ações propostas caminham na direção de se pensar a cidadania aliada a movimentos sociais e à organização social. A criança terá que se deslocar de sua escola para pensar sua comunidade, sua casa, sua família, seus amigos, vizinhos, seu bairro etc. num esforço conjunto de análise que de fato promova tanto a tância do seu nome, de desenhar a si mesma, mostrando à criança/adolescente a sua importância enquanto cidadão, valorizando sua história pessoal de vida e a história de sua família. Com esta discussão inicial já temos possibilidade de avançar nos conceitos de família e grupo social, referindo à diversidade dos modelos familiares para então pensar na diversidade dos grupos sociais. A partir de então é possível discutir a cidadania partindo da reflexão de quem é o cidadão, quem a criança/adolescente reconhece como cidadão e o que ele faz, a fim de estabelecer os seus critérios para a sua definição de cidadão e cidadã.

Por exemplo, no tópico Cidadania, o Caderno sugere a construção de um painel para colar figuras em dois lados - em um lado a criança/adolescente cola as figuras que considere relacionadas com o ser e o fazer do cidadão/cidadã, e do outro lado as figuras que considerem negativas de acordo com sua idéia de cidadão/ cidadã. É a partir dessa atividade que a turma sintetiza seu próprio conceito de cidadania, como mostram as páginas abaixo reproduzidas:

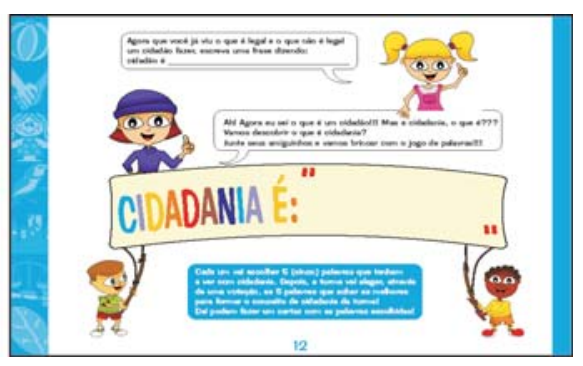

interação com o cotidiano da criança/adolescente como a crítica deste mesmo cotidiano. Assim, o intuito é de gerar ações de intervenção direta no sentido da crítica e do melhoramento do meio em que vive, e de como ela pode ser um agente transformador. Neste sentido, é salutar concordar com Freire quando afirma que 
Pensar certo coloca ao professor ou mais amplamente, à escola, o dever não só de respeitar os saberes com que os educandos, sobretudo os das classes populares, chegam a ela - saberes socialmente constituídos na prática comunitária, mas também discutir com os alunos a razão de ser de alguns desses saberes em relação com o ensino dos conteúdos. Porque não estabelecer, uma necessária "intimidade" entre os saberes curriculares fundamentais aos alunos e a experiência social que eles têm como indivíduos? (FREIRE, 2002, p. 33-34).

Entende-se que, mais que possuir um bom recurso teórico-metodológico, o Caderno deve retratar a realidade local propiciando uma reflexão a partir da própria percepção e vivência das crianças e adolescentes em suas comunidades. Por exemplo, o problema dos pescadores artesanais e os diversos tipos de dano ao meio-ambiente, a falta de uma associação de moradores em alguns bairros, o desconhecimento da Agenda 21 Mirim e do próprio Estatuto da Criança e do Adolescente, esclarecimentos acerca dos Direitos Humanos assim como da Constituição.

Para tanto, cita-se uma atividade que tem por objetivo estimular esta participação no bairro a fim de captar suas potencialidades $e$ deficiências na forma de um "Monitoramento". Se necessário, disponibiliza-se o instrumento reivindicatório do "abaixo-assinado", quando então, após todo trabalho de reconhecimento da comunidade e a percepção do que é bom $e$ do que ainda precisa ser melhorado, estas crianças/adolescentes são "apresentadas" a esta forma popular de reivindicação para "partir para a ação".

Como fruto desta atividade, foi realizado em 2002, numa das escolas originárias do projeto, um abaixo-assinado por parte dos alunos da escola solicitando a construção de uma praça. As crianças participaram de uma Audiência Pública com o Prefeito quando então entregaram o documento. Hoje, após 6 anos, esta praça está no Orçamento Participativo da cidade. Outro exemplo, também refere-se à uma escola local que, por conta da mobilização e reivindicação dos alunos, conseguiram para a escola um novo telhado. Mesmo quando não for possível a realização de todas as reivindicações, terá sem dúvida existido um exercício de participação e construção coletiva. A intenção deste livro é cultivar em cada criança/adolescente, a curiosidade necessária para ir além, uma vez que educar criticamente é possível dentro deste contexto, e ainda aproximar educador e educando, eliminar a imagem do educador como apenas transferidor de conhecimento de maneira verticalizada, e que para os educandos muitas vezes passam como inacessíveis. Seguindo o conselho de Freire:

\begin{abstract}
O fundamental é que professor e alunos saibam que a postura deles, do professor e dos alunos, é dialógica, aberta, curiosa, indagadora e não apassivada, enquanto fala ou enquanto ouve. $\mathrm{O}$ que importa é que o professor e alunos se assumam epistemologicamente. (FREIRE 2002, p. 96)
\end{abstract}

Com a utilização do Caderno é possível trocar experiências e trazer assim o caráter socializante da escola. Assim, o escopo deste projeto é construir, de forma participativa, conhecimentos, habilidades e competências que contribuam para a formação de cidadãos conscientes e ativos na defesa e proteção tanto de seus direitos fundamentais, assegurados pela Constituição, como do patrimônio ambiental. E assim, utilizar-se da escola não apenas como espaço de apreensão de informações técnicoformais, e sim, como de formação $e$ instrumentalização para a cidadania, pois educar é, sobretudo, formar e permitir a participação cidadã.

No entanto, toda a curiosidade de saber exige uma reflexão crítica e prática, de modo 
que o próprio discurso teórico terá de ser aliado à sua aplicação prática. É nesta forma de educar que segue o Programa, com o intuito de levar as crianças/adolescentes a identificarem dentro da sua realidade quais são os problemas e quais as soluções que podem ser por elas encontradas, com isto eles deixam de ser expectadoras e passam a ser autores de sua própria história. Sobre esta discussão, convém observar como a discussão sobre cidadania participativa integra a prática do Caderno de Cidadania.

\section{Cidadania participativa}

A discussão sobre cidadania já é uma tradição na sociedade brasileira que discute $e$ problematiza este conceito de variadas formas. Diante disto, não é necessário discorrer sobre a farta bibliografia que trata do tema, apenas chamar a atenção para algumas particularidades do conceito que são pertinentes ao Caderno de Cidadania. A matriz teórica norteadora do Programa de Formação para a cidadania infantojuvenil revela uma destas particularidades, qual seja a dimensão participativa da cidadania, um potencial ainda tão pouco desenvolvido na sociedade brasileira.

Entretanto, discutir cidadania no alvorecer do século XXI implica em esboçar respostas que dêem conta das amarras sociais que ainda emperram a participação de inúmeros grupos sociais ao acesso e vivência cotidiana da cidadania. Na grande maioria destes grupos sociais, estão crianças e adolescentes condenados à não-cidadania. Pensando neles, o Caderno de
Cidadania foi elaborado para ser utilizado pelas crianças e adolescentes do ensino fundamental das escolas municipais de Itajaí como uma das alternativas de formação para a cidadania que o programa prevê, por meio de treinamentos oferecidos aos professores e gestores educacionais.

A escola pública é considerada por diversos segmentos sociais como o "maior patrimônio popular de um país", mas diante do descaso com a educação a palavra "popular" ganha estigmas como "popular é sinônimo de pobreza" e por isso as escolas públicas não precisam primar pela qualidade de ensino, uma vez que seus alunos já estão em condição de "subalternidade"1, ou como afirma Jessé Souza, já estão em condição de "subcidadania"2. Este estigma reduz o ensino a mero instrucionismo por meio do qual o conhecimento é "repassado", "transmitido" aos alunos, o que gera uma atitude passiva diante do conhecimento e um imobilismo diante da própria sociedade.

Se a escola é uma entidade representativa da sociedade civil, ela deve ser palco não só de discussão e diálogo, mas também de desenvolvimento de hábitos e atitudes transformadoras que podem, na sua persistência e continuidade, formar agentes transformadores de um bairro, de uma cidade, de uma nação e do mundo. Caso contrário, ao invés de avançarmos na conquista de uma cidadania ativa (BENEVIDES,1991) continuaremos reféns de uma cidadania tutelada e assistida (DEMO, 1995) marcada pelo compasso do mercado $e$ da competitividade que, infelizmente, ainda são as marcas da educação pública no Brasil. Para mudar esta realidade, como Demo tem mostrado em suas obras, somente se houver

\footnotetext{
Para Demo, a condição de subalternidade é menos carência material do que incapacidade cidadã. O pobre é, sobretudo, subalterno quando aceita esta condição sem crítica, como situação imutável.

2 A condição de subcidadania para Souza implica na naturalização da desigualdade social no Brasil, que reconhece os direitos e deveres do cidadão, mas o classifica de variadas formas, incluindo os pobres e principalmente os negros na categoria de subcidadão, isto é, cidadãos de segunda categoria.
} 
[...] uma decidida conscientização e educação permanentemente qualificada em torno da formação e correto exercício da cidadania assim como o desenvolvimento comunitário. Neste sentido, torna-se improrrogável planejar e executar programas específicos capazes de favorecer a formação integral e harmônica, democrática, consciente e responsável mediante entre outras alternativas - promoção e formação para cidadania; promoção da cultura e de uma educação que possibilite a todos os cidadãos a sua habilitação para ser pessoa digna, construtiva e solidária, comprometida mediante participação, responsável e generosa, na construção de uma sociedade mais justa, fraterna, democrática e libertadora (DEMO, 1995, p.180-181).

Outro autor central neste debate é Norberto Bobbio. Para o referido autor, na obra A era dos direitos (1992), não adianta falarmos da cidadania como mera retórica. Esse debate não se resume na justificação dos direitos do homem, já consagrados historicamente com a Declaração Universal dos Direitos Humanos, mas falar em cidadania implica especialmente na proteção dos direitos e deveres e "no modo mais seguro para garanti-los, para impedir que, apesar das solenes declarações, eles sejam constantemente violados." (BOBBIO, 1992, p.25). Para que haja essa devida e justa proteção, o autor mostra a necessidade premente de resolver o problema das desigualdades sociais a fim de se obter um eqüitativo desenvolvimento global da civilização humana

Não se pode pôr o problema dos direitos do homem abstraindo-o dos dois grandes problemas de nosso tempo, que são os problemas da guerra e da miséria, do absoluto contraste entre o excesso de potência que criou as condições para uma guerra exterminadora e o excesso de impotência que condena grandes massas humanas à fome. Só nesse contexto é que podemos nos aproximar dos direitos com senso de realismo (BOBBIO, 1992, p.45)

Da mesma forma, Boaventura de Sousa Santos na obra Democratizar a democracia (2002), alude ao mesmo senso de realismo quando fala que o tempo atual é um tempo paradoxal, um tempo de regresso em todos os sentidos (escravatura, servidão, guerras, pandemias...) sendo o principal deles, o sentido da palavra democracia. De fato, o sentido desta palavra se perdeu para grande parcela das crianças e adolescentes brasileiros em condição de pobreza com familias que recebem até $1 / 2$ salário mínimo, como fruto da chamada "questão social", a maldita "herança histórica brasileira da desigualdade" (PAOLI apud SANTOS, 2002, p.388).

Para fazer uma discussão sobre os direitos da criança/adolescente no Brasil com um mínimo de senso de realismo, temos que concordar com a historiadora Mary del Priore quando diz que esta história, desde a época colonial, é permeada mais pela violência do que pela educação "num país onde, há quinhentos anos, a formação social da criança passa mais pela violência explicita ou implícita do que pelo livro, pelo aprendizado e pela educação, raramente aproximam as crianças de conceitos como civilidade e cidadania." (PRIORE, 2000, p.105).

Desta forma, o Caderno de Cidadania tem permitido uma nova escrita na história da formação social da criança e do adolescente uma vez que permite a criação de espaços de cidadania deliberadamente participativos, seja nos bancos escolares como nas entidades que usam o Caderno de Cidadania diretamente com as crianças por elas atendidas.

Esta experiência encontra-se em andamento em um bairro popular do Município de Itajaí, o bairro Nossa Senhora das Graças, onde o Caderno de Cidadania é utilizado no espaço físico da Associação de Moradores aos sábados pela manhã. Nesta comunidade, realiza-se um Curso de Arte e Cidadania para despertar e 
estimular a prática da cidadania nos vários aspectos que o Caderno propõe em cada módulo. A utilização do Caderno pelas crianças é coordenada pelos bolsistas do Programa e atende em torno de 15 crianças.

O Curso, em realização desde maio/ 2007, utiliza em conjunto o primeiro Módulo e o terceiro Módulo, isto é, as atividades são pensadas a partir dos temas ambientais e da ação coletiva. Possibilita-se a estas crianças/adolescentes a oportunidade de sonhar com um bairro em melhores condições com o objetivo principal de desconstruir a visão negativista de mundo ofertado à população de baixa renda, especialmente a visão conformista de que "as coisas são assim mesmo" para a visão de que "as coisas ESTÃO assim, mas podem mudar." É Freire (2002, p.85) quem, mais uma vez, ensina que "não sou apenas objeto da história, mas seu sujeito igualmente," podendo desta forma participar ativamente da história:

E não se trata obviamente de impor à população que se rebele, que se mobilize, que se organize para defender-se, vale dizer que para mudar o mundo. Trata-se na verdade - não importa se trabalhamos com alfabetização, com saúde, com evangelização ou com todas elas - de si- multaneamente com o trabalho especifico de cada um desses campos, desafiar os grupos populares para que percebam, em termos críticos, a violência e a profunda injustiça que caracterizam sua situação concreta. Mais ainda, que sua situação concreta não é destino certo ou vontade de Deus, algo que não poderá ser mudado (Freire, 2002, p.89)

\section{Resultados obtidos: qualitativos e quan- titativos}

A convite da Secretaria da Educação do Município de Itajaí, por intermédio de sua Coordenação de Projetos para o Ensino Fundamental, a primeira Oficina realizada que deu início às atividades do Programa de Formação foi a Oficina de Capacitação do Caderno de Cidadania realizada em julho de 2006 durante o X Seminário Municipal de Educação: Escola, Espaço de Mudanças e Conquistas, nas dependências da Univali. A Oficina, que totalizou uma carga horária de 8 horas com 81 participantes, dentre professores e gestores municipais, é o ponto de partida para a discussão referente aos resultados qualitativos e quantitativos do projeto. 


\begin{tabular}{|c|c|}
\hline Qualitativos & Quantitativos \\
\hline $\begin{array}{l}\text { Utilização do Caderno de Cidadania como } \\
\text { instrumento facilitador para a cidadania } \\
\text { participativa. }\end{array}$ & $\begin{array}{l}81 \text { participantes formados. } \\
48 \text { parceiros definidos que representavam } 13 \\
\text { escolas. }\end{array}$ \\
\hline $\begin{array}{l}\text { Fechamento de parcerias com as escolas e } \\
\text { entidades municipais. }\end{array}$ & $\begin{array}{l}\text { Das } 13 \text { escolas contactadas na Oficina, } \\
04 \text { firmaram as parcerias e receberam } \\
04 \text { capacitações durante o primeiro semestre de } \\
2007 . \\
\text { Doação de } 2.000 \text { Cadernos para as escolas e } \\
\text { entidades parceiras. } \\
\text { Doação de } 1.000 \text { Cadernos para divulgação } \\
\text { entre os gestores das escolas e da Universidade. }\end{array}$ \\
\hline $\begin{array}{l}\text { Retomada do contato com as duas escolas } \\
\text { originárias do Projeto com vistas a oferecer o } \\
\text { retorno social do mesmo. }\end{array}$ & $\begin{array}{l}2 \text { oficinas para } 20 \text { professores das } 2 \text { escolas } \\
\text { originárias. } \\
\text { Interesse dos alunos que participaram dos } \\
\text { projetos que deram origem ao Programa de } \\
\text { Formação. } \\
\text { Doação de } 1.000 \text { Cadernos para as escolas. }\end{array}$ \\
\hline $\begin{array}{l}\text { Filmagem nas escolas e entidades parceiras } \\
\text { para divulgação do alcance social do Caderno } \\
\text { de Cidadania. }\end{array}$ & $\begin{array}{l}\text { Realização de } 2 \text { entrev istas para o Canal Futura } \\
\text { com uma escola e uma ONG parceira do projeto } \\
\text { Realização de } 4 \text { entrevistas de divulgação do } \\
\text { Programa para jornais locais e da Univali. } \\
\text { Realização de } 1 \text { entrevista para o Jornal da } \\
\text { Assembléia Legislativa de SC. }\end{array}$ \\
\hline $\begin{array}{l}\text { Atendimento a deman da de escolas, entidades, } \\
\text { ONG etc. que desejavam ser parceiras do } \\
\text { Programa. }\end{array}$ & Realização de 4 oficinas com os novos parceiros. \\
\hline $\begin{array}{l}\text { Realização de atividades educativas no bairro } \\
\text { Nossa Senhora das Graças com o Caderno de } \\
\text { Cidadania com vistas ao desenvolvimento da } \\
\text { autonomia infanto-juvenil das crianças e } \\
\text { adolescentes do bairro. }\end{array}$ & $\begin{array}{l}\text { Realização de um curso com duração de } 6 \\
\text { meses. } \\
\text { Realização de } 30 \text { Oficinas com } 15 \text { crianças. } \\
\text { Doação de } 15 \text { Cadernos para cada criança. }\end{array}$ \\
\hline $\begin{array}{l}\text { Término do Livro dos Multiplicadores que será } \\
\text { doado aos parceiros. }\end{array}$ & $\begin{array}{l}\text { Diagramação do Livro para posterior publicação } \\
\text { de } 3 \text { mil exemplares. }\end{array}$ \\
\hline
\end{tabular}

\section{Benefícios sociais alcançados pelo pro- jeto}

Após a publicação do Caderno, em 2006, as parcerias firmadas em 2007 demostram que uma outra cidadania para crianças e adolescentes é possível. Seja na escola, ou na comunidade, o importante é perceber que se caminha para a consolidação de uma rede que está dinamizando e potencializando as crianças e adolescentes como cidadãos autônomos e conscientes de seu papel na sociedade. A parceria com as escolas traduz o esforço em contribuir para o enfrentamento dos problemas de exclusão e violência infantil por meio de uma nova ferramenta pedagógica.

\section{Considerações finais}

Diante dessa realidade, a inserção deste projeto junto à população infanto-juvenil tem possibilitado a criação de espaços de ação-reflexão-intervenção nas comunidades e nas escolas ao permitir o desenvolvimento da autonomia e da tomada de consciência da cidadania das crianças e adolescentes frente à sua realidade. O Programa tem contribuído para a formação de multiplicadores do Caderno de Cidadania por Oficinas que permitem a construção conjunta de conhecimentos e da disponibilização de informações necessárias à plena formação do cidadão. Neste sentido, o direito da criança e do adolescente se apresen- 
ta como uma das mais importantes discussões dentro do âmbito sócio-político e jurídico que necessita de ações integradas. Visando o seu fortalecimento e divulgação como uma das for-

\section{REFERÊNCIAS}

BENEVIDES, Maria V. de M. A cidadania ativa: Referendo, plebiscito e iniciativa popular. São Paulo: Ática, 2003.

BOBBIO, Norberto. A era dos direitos. São Paulo: Ática, 1999.

CANDAU, V. M. et al. Tecendo a cidadania: oficinas pedagógicas de direitos humanos. Petrópolis: Vozes, 1995

DEMO, Pedro. Cidadania Tutelada e Cidadania Assistida. Campinas: Autores Associados, 1995, v.1 mas de promoção da cidadania e da luta contra a situação de vulnerabilidade social a que está submetida grande parte da população infanto-juvenil brasileira.
FREIRE, Paulo. Pedagogia da Autonomia. 22. ed, São Paulo: Paz e Terra S/A, 2002.

PRIORE, Mary del. História da Criança no Brasil. São Paulo: Contexto, 2002.

SANTOS, Boaventura de S.(org) Democratizar a democracia. Rio de Janeiro: Civ. Brasileira, 2002.

Texto recebido em 09 jan. 2008.

Texto aprovado em 19 mar. 2008. 